OPEN ACCESS

Edited by:

Ruowen Zhang,

Southern Research Institute,

United States

Reviewed by:

Rong Zhang,

Shenyang Pharmaceutical University,

China

Dongqing Wang,

GeneDx, United States

${ }^{*}$ Correspondence:

Hua-chuan Zheng

zheng_huachuan@hotmail.com

Specialty section:

This article was submitted to Molecular and Cellular Oncology,

a section of the journal

Frontiers in Oncology

Received: 29 August 2020

Accepted: 09 October 2020

Published: 30 November 2020

Citation:

Zhao S, Hao C-I, Zhao E-h, Jiang H-m and Zheng $\mathrm{H}-\mathrm{C}$ (2020) The

Suppressing Effects of Dkk3

Expression on Aggressiveness and Tumorigenesis of Colorectal Cancer.

Front. Oncol. 10:600322.

doi: 10.3389/fonc.2020.600322

\section{The Suppressing Effects of Dkk3 Expression on Aggressiveness and Tumorigenesis of Colorectal Cancer}

\author{
Shuang Zhao ${ }^{1}$, Chang-lai Hao ${ }^{2}$, En-hong Zhao ${ }^{3}$, Hua-mao Jiang ${ }^{4}$ and Hua-chuan Zheng ${ }^{1 *}$ \\ 1 Department of Oncology and Experimental Center, The Affiliated Hospital of Chengde Medical University, Chengde, China, \\ 2 Department of Hematology, The Affiliated Hospital of Chengde Medical University, Chengde, China, ${ }^{3}$ Department of \\ Surgery, The Affiliated Hospital of Chengde Medical University, Chengde, China, ${ }^{4}$ Department of Urology, The First Affiliated \\ Hospital of Jinzhou Medical University, Jinzhou, China
}

Dkk3 has been discovered during comparison of immortalized and parental cells. Its expression has been shown to reduce colony formation and induce apoptosis of cancer cells, acting as a tumor suppressor. Herein, we demonstrate that Dkk3 overexpression or protein treatment may inhibit colorectal cancer cell proliferation, migration, and invasion and that they may promote apoptosis and $\mathrm{G}_{2}$ phase arrest with hypoexpression of $\mathrm{Bcl}-2$, cdc25B, cdc25c, N-cadherin, slug, and twist and hyperexpression of Bax and $\mathrm{E}-$ cadherin. This effect is consistent with that of recombinant Dkk3 exposure and blocked with anti-Dkk3 antibody. Dkk3 deletion in intestinal cells was not associated with the emergence of epithelial lesions; however, adenoma emerged after sodium desoxycholate treatment. At both mRNA and protein levels, Dkk3 expression was higher in normal than in cancer tissues $(p<0.05)$. Dkk3 mRNA expression was negatively associated with its promoter methylation, growth pattern, differentiation, and favorable prognosis in the patients with colorectal cancer $(p<0.05)$. Dkk3-related signal pathways in colorectal cancer included those of cellular adhesion and migration, melanogenesis, chemokine, Hedgehog, JAK-STAT, TOLL-like receptor, TGF- $\beta$, MAPK, and calcium signaling $(p<0.05)$. These findings indicate that Dkk3 expression levels can help assess cancer aggressiveness and patient prognosis. It might also suppress aggressive phenotypes and tumorigenesis as a molecular target in gene therapy.

Keywords: Dkk3, colorectal cancer, tumorigenesis, aggressive phenotypes, pathological behaviors, prognosis

\section{INTRODUCTION}

Dkk3 was discovered by representational difference PCR analysis; its mRNA expression has been shown as downregulated in immortalized cells compared to control (1). A homology alignment indicates that $D k k 3$ is identical with reduced expression in immortalized cells (REIC). Dkk3 cDNA encodes a secreted glycoprotein with five potential $\mathrm{N}$-glycosylation sites, an $\mathrm{N}$-terminal signal peptide, two cysteine-rich domains, and two coiled-coil domains (2). TNF- $\alpha$ downregulated Dkk3 expression 
in normal skin keratinocytes and mouse skin and hair culture models, which was abrogated by anti-TNF- $\alpha$ antibody (3). In prostate cancer cells, Dkk3 expression inhibited cell proliferation and tumor growth, induced apoptosis, and sensitized cells to doxorubicin by c-JNK activation, mitochondrial redistribution of Bax, or by triggering Bcl-2 hypoexpression (4).

Previous studies have reported that Dkk3 induced JNK activation via endoplasmic reticulum (ER) stress and mitochondrial pathways (4-6). Takata et al. (7) demonstrated that DKK3 initiated apoptosis via mitochondrial and Fas death receptor pathways in mucinous ovarian carcinoma cells. Exogenous Dkk3 inhibited Wnt/ $\beta$-catenin signaling and cell proliferation in kidney cancer cells (8), and the cysteine-rich core domain of Dkk3 was required for dendritic cell-like differentiation from monocytes and for tumor regression, where it activated phosphorylation of GSK-3 $\beta$ and stat (9). Meanwhile, adeno-Dkk3 virus has been shown to inhibit tumor growth and lymph node metastasis and prolong survival in nude mice with prostate cancer by inducing apoptosis, suppressing cell invasion and migration, and decreasing MMP2 activity (10).

Dkk3 protein is expressed in the brain, heart, kidney, mammary gland, liver, pancreas, and lymph node (11). Its expression has been reported as downregulated in cancer cells, including in hepatocellular carcinoma, renal clear cell carcinoma, cervical squamous carcinoma, non-small cell lung cancer, and seminoma (12-17). In gastric cancer, Dkk3 overexpression or Dkk3 treatment decreased the karyoplasmic ratio, cell proliferation, migration, invasion, and lamellipodia formation and increased the likelihood of $\mathrm{G}_{1}$ phase arrest and apoptosis, which were blocked by anti-Dkk3 antibody. Dkk3 knockdown caused the opposite effect in immortalized gastric epithelial cells. Immunohistochemically, the level of Dkk3 expression was inversely correlated with tumor size, lymph node involvement, cell dedifferentiation, and unfavorable prognosis in gastric cancer. Moreover, serum Dkk3 concentration has been reported as remarkably higher in age-matched controls than in gastric cancer patients, where it was inversely associated with tumor size (18).

Colorectal cancer is a type of cancer associated with high risk of mortality $(19,20)$. Although colorectal adenoma pathologically and genetically precedes adenocarcinoma, its molecular mechanisms remain elusive. Previously, we have shown that Dkk3 expression was remarkably downregulated in colorectal non-neoplastic mucosa, adenoma to adenocarcinoma, and negatively correlated with invasion depth, TNM stage, and colorectal cancer cell dedifferentiation rate (21). Herein, we observed in vitro and in vivo the effects of Dkk3 expression and recombinant Dkk3 treatment on aggressive phenotypes of colorectal cancer cells, aiming to clarify the molecular mechanisms involved. Additionally, we established a mouse model of conditional $D k k 3$ knockout in intestinal epithelial cells, using villin promoter to initiate cre recombination. Finally, pathological and bioinformatics analyses were performed to explore clinicopathological or prognostic significances of Dkk3 expression.

\section{MATERIALS AND METHODS}

\section{Cell Culture}

Colorectal cancer cell lines (HCT-15 and HCT-116) were isolated from the same colorectal cancer patients with Duke's $\mathrm{C}$ and purchased from the Cell Bank of Chinese Academy of Sciences, Shanghai, China. They were cultured in RPMI 1640 medium containing FBS, penicillin, and streptomycin in $5 \% \mathrm{CO}_{2}$ at $37^{\circ} \mathrm{C}$. Both kinds of cells were transfected with pCDNA3.1Dkk3 and pcDNA3.1 at $70 \%$ confluence $24 \mathrm{~h}$ after seeding on dishes according to the manufacturer's instructions (QIAGEN, USA). Both HCT-15 and HCT-116 were treated with recombinant Dkk3 (R\&D Systems, 1118-DK, USA) in RPMI 1640 at a dose of $50,100,150$, or $200 \mathrm{ng} / \mathrm{mL}$ or their Dkk3 transfectants were exposed to anti-Dkk3 antibody (R\&D Systems) at a dose of 30 or $60 \mathrm{ng} / \mathrm{mL}$. Nontreated HCT-15 and HCT-116 cells were considered as control and pcDNA3.1 transfectant as mock.

\section{Immunofluorescence}

Cells were attached to glass coverslips and fixed with $4 \%$ neutral formaldehyde and permeabilized with $0.2 \%$ Triton X-100. After washing with PBS, cells were incubated overnight at $4^{\circ} \mathrm{C}$ with goat anti-Dkk3 antibody (R\&D system) and subsequently with antigoat IgG-FITC antibody (Santa Cruz) at room temperature and then stained with DAPI for nuclear labeling. Finally, we mounted coverslips with SlowFade ${ }^{\circledR}$ Gold antifade reagent (Invitrogen) and observed them using a laser confocal microscope.

\section{ELISA Assay}

Human Dkk-3 DuoSet ELISA Kit (R\&D Systems) was employed to detect the Dkk3 level of cell culture supernatant and patient serum.

\section{Proliferation Assay}

We used cell counting kit-8 (CCK-8) to determine cell proliferation. In brief, $2.0 \times 10^{3}$ cells/well were cultured on a 96-well plate. After adhering to the plate, $10 \mu \mathrm{L}$ of CCK-8 solution was added to each well at a different time point; absorbance was measured at $450 \mathrm{~nm}$ after $3 \mathrm{~h}$ incubation.

\section{Cell Cycle Analysis}

We trypsinized, collected, and fixed the cell line using ethanol for $2 \mathrm{~h}$. After RNase treatment for $1 \mathrm{~h}$, cells were pelleted and stained by propidium iodide (PI) for $30 \mathrm{~min}$. Finally, flow cytometry was used to examine the PI signal.

\section{Apoptosis Assay}

FITC-labeled annexin V staining (BD Pharmingen) was employed to indicate phosphatidylserine externalization of early apoptosis. In brief, $1 \times 10^{6}$ cells were collected, washed with PBS, and pelleted. FITC-labeled annexin V $(5 \mu \mathrm{L}$, final concentration: $1 \mathrm{ug} / \mathrm{mL})$ and PI $(5 \mu \mathrm{L}$, final concentration: $50 \mu \mathrm{g} /$ $\mathrm{mL}$ ) were added to cell suspension, mixed, incubated for $15 \mathrm{~min}$, and examined by flow cytometry. 


\section{Mitochondiral Membrane Potential}

We determined the mitochondrial membrane potential using JC1 Mitochondrial Membrane Potential Assay Kit (Kagen, China). In brief, cells were stained by JC-1 $(100 \mathrm{uL} / \mathrm{mL})$ for $30 \mathrm{~min}$ and harvested for flow cytometry with JC-1 monomer (green, low concentration in cytosol) as FL1 channel and JC-1 aggregates (red, high concentration in mitochondria) as FL2 channel. In addition, the harvested cells were prepared as slides and observed under a fluorescence microscope.

\section{Transwell Chamber Assay}

To assess the extent of cell invasion, we cultured $2.0 \times 10^{5}$ cells in FBS-free medium in the matrigel-coated insert on the chamber top and added 10\% FBS-containing medium to the chamber bottom as a chemoattractant. After $24 \mathrm{~h}$ incubation, the upper part of the insert was scrubbed, and the lower part was fixed in methanol, followed by Giemsa dye. To measure capacity for cell migration, we repeated this procedure without the membrane control insert.

\section{Animals}

We housed three mice per plastic cage, which included paper chips, standard rodent food, and water provided in pathogenfree and temperature-controlled conditions with a 12-h light/ dark illumination cycle. All experiments involving mice were approved by the Committee on Animal Experimentation of the Affiliated Hospital of Chengde Medical University. We performed cre- mediated deletion of floxed alleles in a germline by mating $D k k 3$ conditional mutants (kindly presented by Prof. Kumon) with villin (intestine-specific)-cre mice (Jax Lab). At least 5 mice were sacrificed at 9 months, and their intestines were histologically analyzed. To chemically induce colorectal tumor, we orally administrated sodium desoxycholate in $0.09 \%$ agarose suspension to male villin-cre/ $D k k 3$ ( $n=5,16-18 \mathrm{~g}$, age 8 weeks) and wild-type (WT, $n=5,16-$ $18 \mathrm{~g}$, age 8 weeks) mice for 6 weeks. After 40 weeks, these mice were sacrificed, and their colorectal tissues were subjected to pathological examination, RNA, and protein extraction.

\section{Subjects}

Colorectal cancer and paired normal mucosa $(n=107)$ tissues were sampled from surgical resection specimens, acquired at the Affiliated Hospital of Chengde Medical University between 2017 and 2019. The patients with CRC were 59 men and 48 women (22 85 years, mean=62.9 years). Among them, 47 cases are accompanied with lymph node metastasis. These cases included well $(n=19)$, moderately $(n=60)$, and poorly $(n=12)$ differentiated; mucinous $(n=7)$; and other $(n=9)$ adenocarcinomas. Serum samples were obtained before surgery from 13 patients with colorectal cancer and 40 healthy individuals attending Affiliated Hospital of Chengde Medical University. None of the patients had undergone chemotherapy, radiotherapy, or any other treatment before the operation. All participants provided comprehensive consent to participate in research and for their data to be used further. The study protocol was approved by the Ethics Committee of the Affiliated Hospital of Chengde Medical University.

\section{DNA Analysis}

DNA was extracted from mouse tail and intestine using the phenol-chloroform method. We performed genotyping by PCR. The PCR primer sequences were CSD-lacF: 5'-GCTACCATTAC CAGTTGGTCTGGTGTC-3', CSD-neoF: 5'-GGGATCTCA TGCTGGAGTTCTTCG-3', CSD- loxF:5'-GAGATGGCGCAA CGCAATTAATG-3', CSD-Dkk3-R:5'-AACAGGAGATTC CAGGT GTCAGAGG-3', CSD-Dkk3-ttR: 5'-GCCTGGCCAG CACTTTTATCTATCC-3', CSD-Dkk3-F: 5'-TCTGCTTTA GCCATACCTCTTGGGG-3', Dkk3-F: 5'-ACCAAAGGTG GCAATGGGACC ATCT-3', Dkk3-R: 5'-GGTGGAAAGC ACTCTAAGGCCCAGC-3', cre: 5'-GCCTGCATTACC GGTCGATGC-3' and 5'-CAGGGTGTTATAAGCAATCCC-3'. The presence of truncated $D k k 3$ and cre was confirmed by tail DNA PCR. Dkk3 deletion was confirmed by PCR amplification of intestinal mucosa DNA.

\section{Real-Time RT-PCR}

We extracted total RNA from cells and tissues using Trizol (Takara). Reverse transcription of $1 \mu \mathrm{g}$ RNA was performed using random primers and AMV reverse transcriptase. PCR primers were designed according to the sequences provided by GenBank. The oligonucleotide primer forward sequence was 5'ACAGCCACAGCCTGGTGTA-3'. The reversed primer sequences were 5'-CC TCCATGAAGCTGCCAAC-3' for Dkk3 (120 bp), 5'-TAGAATTGGTAGTTCTTCAT-3' and 5'-A TTG CATCCCAGACAGTG-3' for N-cadherin (100 bp), and 5'CAGGTCTCCTCATGGCTT-3' and 5'-CATCCTTAAATC TCACTCT -3' for E-cadherin (140 bp). For internal control, $G A P D H$, forward primer sequences were 5'-CAATGACCCCT TCATTGACC-3'; reversed sequences were 5'-TGGAAGATGG TGATGGGATT-3’ (135 bp). SYBR Premix Ex Taq II kit (Takara) was used to amplify GAPDH as an internal control.

\section{Western Blot}

Protein was extracted in RIPA lysis buffer and identified by BCA assay. We separated denatured protein in SDS-polyacrylamide gel and transferred it to the Hybond membrane, which was blocked with $5 \%$ milk in TBST. For immunoblotting, the membrane was incubated for $1 \mathrm{~h}$ with mouse anti-Bax (Santa Cruz), rabbit anti-cdc25B (H-85, Santa Cruz), anti-cdc25C (C20, Santa Cruz), anti-E-cadherin (Cell Signaling Technology), anti-N-cadherin (Cell Signaling Technology), anti-slug (Cell Signaling Technology), anti-twist1 (Cell Signaling Technology), or anti-GAPDH (Santa Cruz) antibody for $1 \mathrm{~h}$ in TBST at room temperature. Subsequently, these membranes were incubated with antimouse or antirabbit IgG conjugated to horseradish peroxidase (Dako) for $1 \mathrm{~h}$ at room temperature. Bands were visualized using ECL- Plus (Santa Cruz).

\section{Histological Analysis}

Tissues were subjected to routine pathological block preparation. Consecutive sections were deparaffinized, dehydrated, and subjected to immunostaining as previously described (18) or to the TUNEL procedure, using ApopTag Plus Peroxidase in Situ Apoptosis Detection Kit (Millipore) as recommended. 


\section{Bioinformatics Analysis}

The differences in level of Dkk3 expression were examined between colorectal normal and colorectal cancer tissues using Oncomine (www.oncomine.com). Data on the rate of expression (RNA-seqV2) and methylation as well as data on clinicopathological characteristics of colorectal cancer patients were extracted from the TCGA database using TCGA-assembler in $\mathrm{R}$ software. We integrated our raw data and examined Dkk3 expression levels in colorectal cancer tissue, which were subsequently examined against patient clinicopathological and prognostic characteristics. The Kaplan-Meier method was used to examine the prognostic significance of Dkk3 mRNA expression. Moreover, we used these data to examine the rate of promoter methylation and to perform GSEA. Based on Dkk3 expression levels, the data were divided into high- and lowexpression groups based on the median value of colorectal cancer patients. GSEA was performed with GSEA-3.0. The impact of $D k k 3$ methylation and expression on survival rates was examined using methylation, clinical, and transcriptome data. Methylated and unmethylated signals were employed to calculate $\beta$ coefficients, which are a quantitative representation of DNA methylation levels. Cutoff values were defined as median values of $\beta$-coefficients and mRNA expression levels. Kaplan-Meier survival curves of $D k k 3$ methylation were obtained as well.

\section{Statistical Analyses}

We repeated 3 different experiments to calculate mean and standard deviation. Statistical analysis was performed using Mann-Whitney $U$ to differentiate the means and log-rank statistic to compare the survival rate. We used SPSS 10.0 for data analysis. $P$-values $<0.05$ were considered indicative of statistical significance.

\section{RESULTS}

\section{Dkk3 Expression and Aggressive Colorectal Cancer Cell Phenotype}

After transfection with pcDNA3.1-Dkk3, HCT-15, and HCT-116 cells overexpressed Dkk3 protein by western blot using antiDkk3 or anti-His antibody (Figure 1A). In Dkk3 transfectants, mRNA levels increased 7- to 13-fold compared to those in the control cells (Figure 1B, $p<0.05$ ). Immunofluorescence testing showed higher levels of Dkk3 expression in the cytoplasm of transfectants than in that of control or mock cells (Figure 1C, $p<0.05)$. The cell culture supernatant of Dkk3 tranfectants had a higher Dkk3 concentration than that of control or mock cells (Figure 1D, $p<0.05$ ). However, a higher level of Dkk3 expression was detected in the serum of colorectal cancer patients than in that of healthy controls regardless of age (Figure 1E, $p<0.05$ ). The rate of growth of Dkk3 transfectants was slower than that of control and mock cells (Figure 1F, $p<0.05$ ). Cell cycle analysis indicated $G_{2}$ phase arrest in the transfectants but not in the control or mock cells (Figure 1G, $p<0.05$ ). There was a high rate of apoptosis in HCT-15 and HCT-116 cells after Dkk3 transfection (Figure 1H, $p<0.05$ ),. JC-1 staining demonstrated that Dkk3 expression significantly reduced mitochondrial membrane potential in these cells (Figures 1I, J). Compared with control and mock cells, Dkk3 overexpression suppressed migration and invasion capacities of both colorectal cancer cell types (Figures $\mathbf{1 K}, \mathbf{L}, p<0.05$ ). Finally, treatment of Dkk3 transfectants with anti-Dkk3 antibody resulted in blocked effects of Dkk3 overexpression on these phenotypes (Figures 1F-L, $p<0.05$ ).

\section{Recombinant Dkk3 and Aggressive Colorectal Cancer Cell Phenotypes}

Treatment with recombinant Dkk3 protein significantly suppressed the proliferation of HCT-15 and HCT-116 cells (Figure 2A, $p<0.05$ ). Exposure to Dkk3 protein resulted in $\mathrm{G}_{2}$ phase arrest in HCT-15 and HCT-116 cells in a dose-dependent manner (Figure $\mathbf{2 B}, p<0.05$ ). In addition, there was a higher level of apoptosis in HCT-15 and HCT-116 cells treated with Dkk3 protein (Figure $\mathbf{2 C}, p<0.05$ ) than in the control cells. JC-1 staining also demonstrated that Dkk3 exposure significantly reduced the mitochondrial membrane potential of these cells (Figures 2D, E, $p<0.05)$. In compare to control cells, Dkk3 protein exposure suppressed migration and invasion capacity of both colorectal cancer cell types (Figures 2F, G, $p<0.05$ ).

\section{Dkk3 and Expression of Phenotype- Related Proteins in Colorectal Cancer Cells}

As indicated in Figure 3, Dkk3 overexpression and treatment decreased the levels of expression of Bcl-2, cdc25B, cdc25c, Ncadherin, slug, and twist; in contrast, it increased the levels of expression of Bax and E-cadherin in HCT-15 and HCT-116 cells. Use of anti-Dkk3 antibody suppressed the effects of Dkk3 overexpression on these phenotype-related proteins.

\section{The Effects of Dkk3 on Colorectal Carcinogenesis}

We matched the conditional $D k k 3-\mathrm{KO}$ mice with villin-cre mice and designed primers to confirm deletion of Dkk3 using DNA from tail and intestinal mucosa (Figure 4A). Using PCR, we confirmed biallelic deletion of $D k k 3$ in intestinal mucosa of Dkk3-villin-cre mice (Figure 4B). Expression levels of Dkk3 and E-cadherin were downregulated in intestinal mucosa of Dkk3-villin-cre at both mRNA and protein levels compared to WT mice; the reverse was observed for $\mathrm{N}$-cadherin expression (Figures 4C, D). However, no remarkable lesions were observed in the intestinal mucosa of either mouse group (data not shown). A single case of colorectal adenoma was observed in villin-cre/ Dkk3 mice after chemical induction, showing a higher level of expression of CDX1, ki-67, and c-erB2 than that observed in normal mucosa (Figure 4E).

\section{Dkk3 Expression in Colorectal Cancer}

$D k k 3$ mRNA expression was examined in colorectal cancer tissues using RT-PCR (Figure 5A). Dkk3 mRNA expression levels were lower in cancer than in normal tissues (Figure 5B, $p<0.05)$. Concurrently, they were higher in tubular than in 

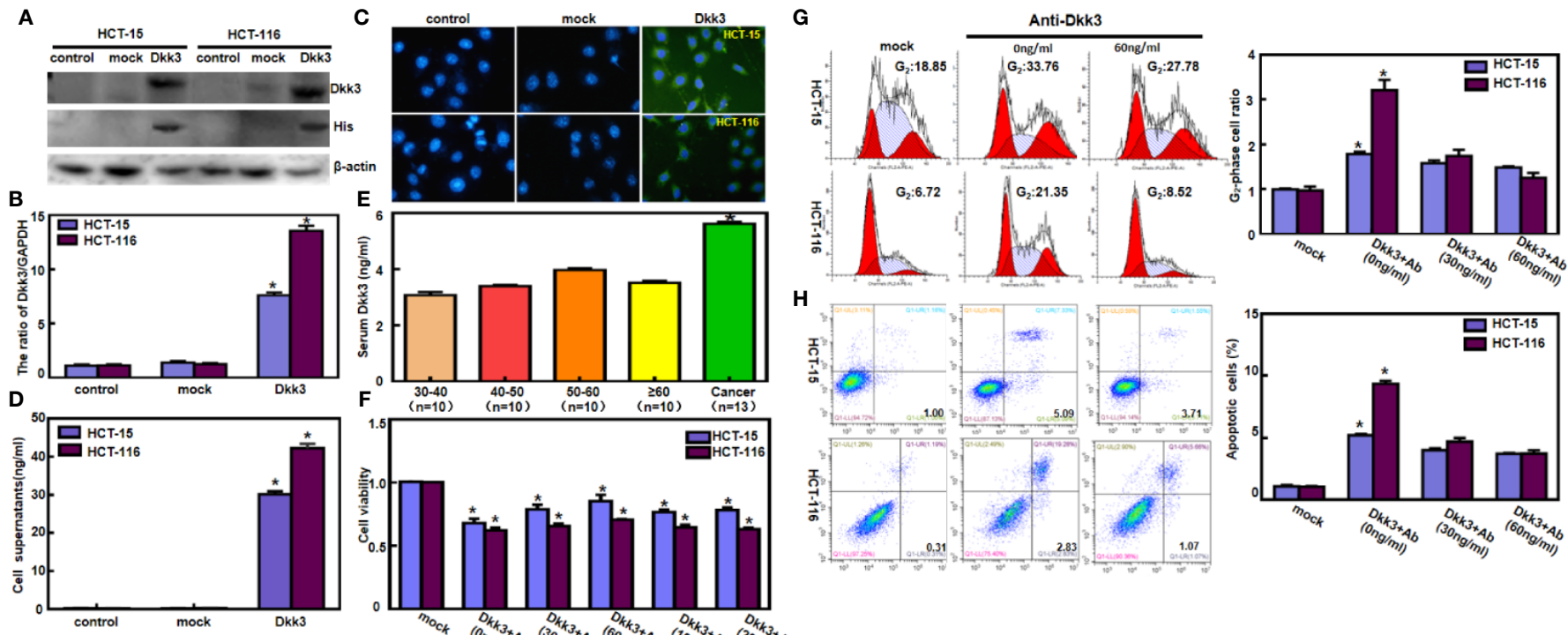

$$
\text { H }
$$
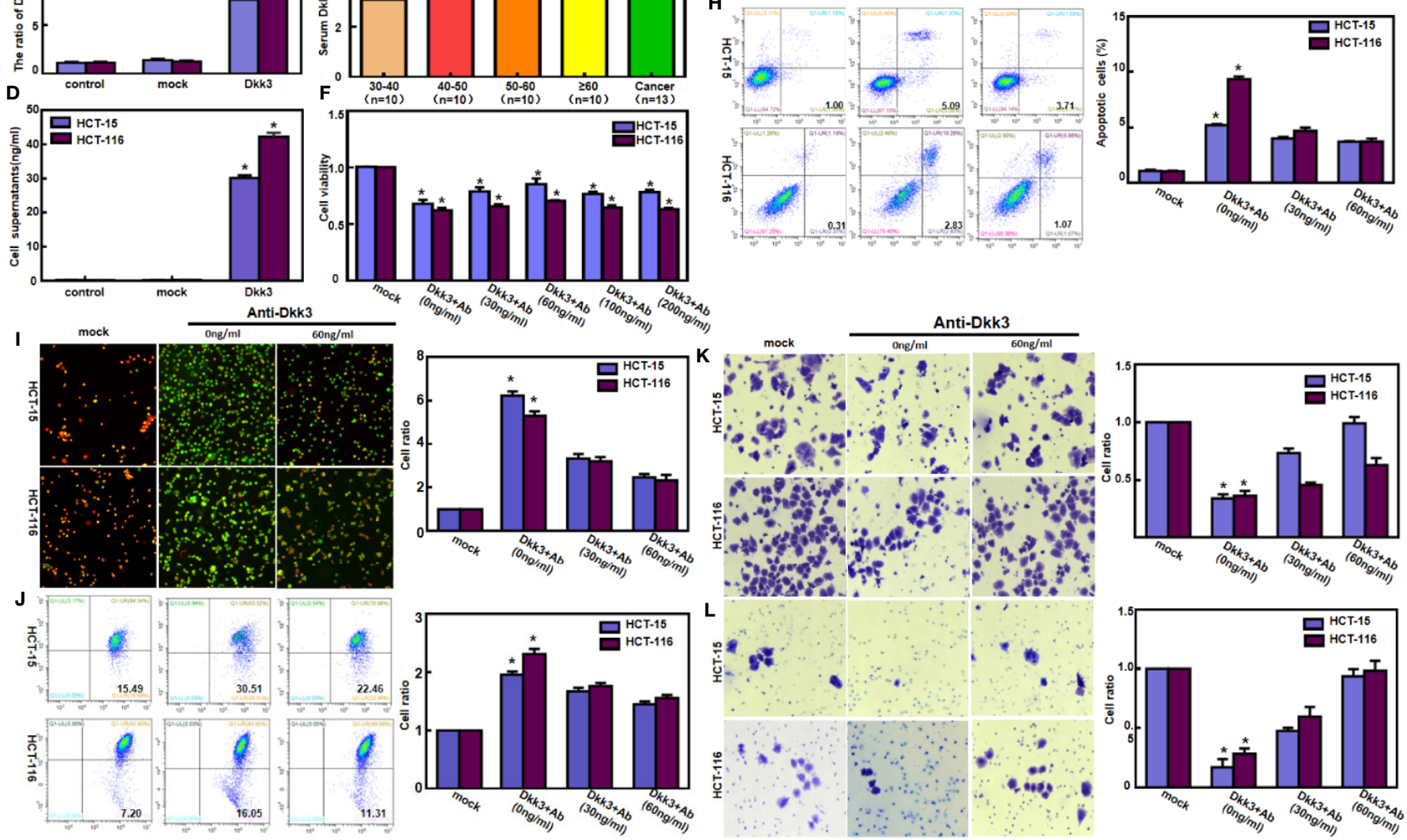

FIGURE 1 | Dkk3 overexpression suppressed the aggressive phenotypes of colorectal cancer cells. After transfection of pcDNA3.1-Dkk3, Dkk3 expression became strong in HCT-15 and HCT-116 cells using anti-Dkk3 and anti-His antibodies by Western blot (A), real-time RT-PCR (B), and immunofluorescence (C, green: positive for Dkk3, blue: DAPI for nuclei). The cell culture supernatant of Dkk3 transfectants showed a higher Dkk3 concentration in comparison with those of the control and mock (D). Colorectal cancer patients showed a higher serum Dkk3 level than healthy individuals regardless of their age, evidenced by ELISA assay (E). The transfectants showed a lower proliferation (F) and $\mathrm{G}_{2}$ arrest (G) in comparison with the control and mock. There was an apoptosis-induced effect of Dkk3 overexpression in the transfectants of HCT-15 and HCT-116, evidenced by annexin $\mathrm{V}$ assay $\mathbf{( H )}$. JC-1 staining displayed that the mitochondrial membrane potential was decreased in the abovementioned cells with Dkk3 overexpression by fluorescence (I) and flow cytometry $\mathbf{( J )}$. Dkk3-overexpressing cells had a weaker ability to migrate (K) and invade (L). We also treated the Dkk3 transfectants with anti-Dkk3 antibody $(0,30$, and $60 \mathrm{ng} / \mathrm{ml})$ and found that this antibody blocked the effects of Dkk3 overexpression on these phenotypes $(\mathbf{F}-\mathbf{L}, p<0.05)$. mock, cells transfected with pcDNA3.1 vector; ${ }^{*} P<0.05$, compared with the control and treatment with anti-Dkk3 antibody. 


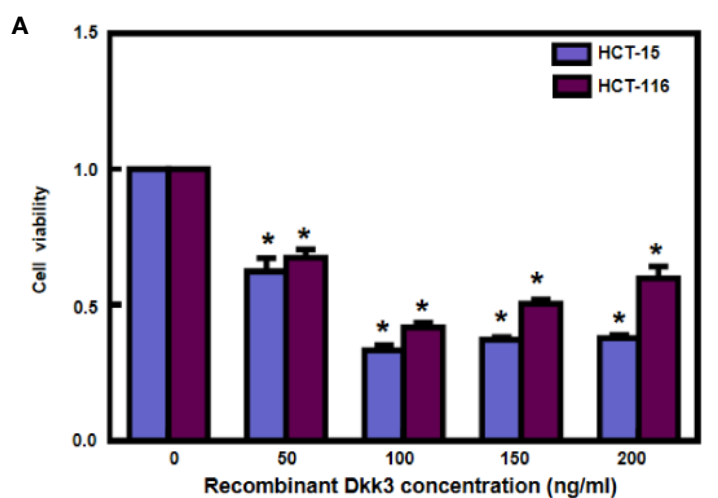

B

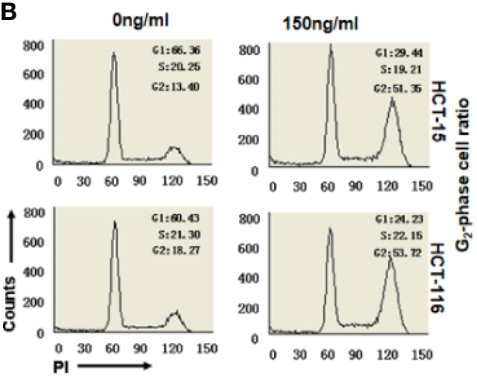

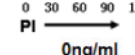

$$
\begin{array}{lll}
0 & 60 & 90 \\
150 \mathrm{ng} / \mathrm{ml}
\end{array}
$$

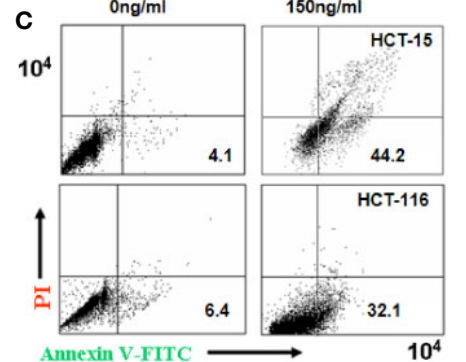

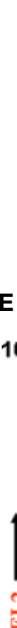

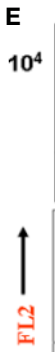
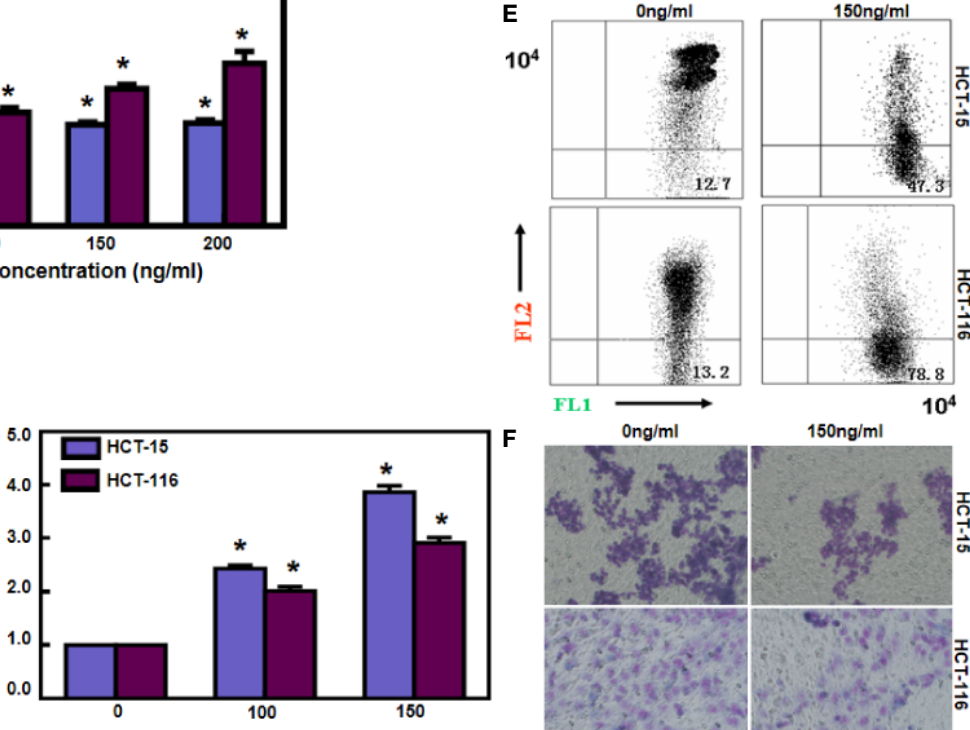

Recombinant Dkk3 concentration (ng/ml)
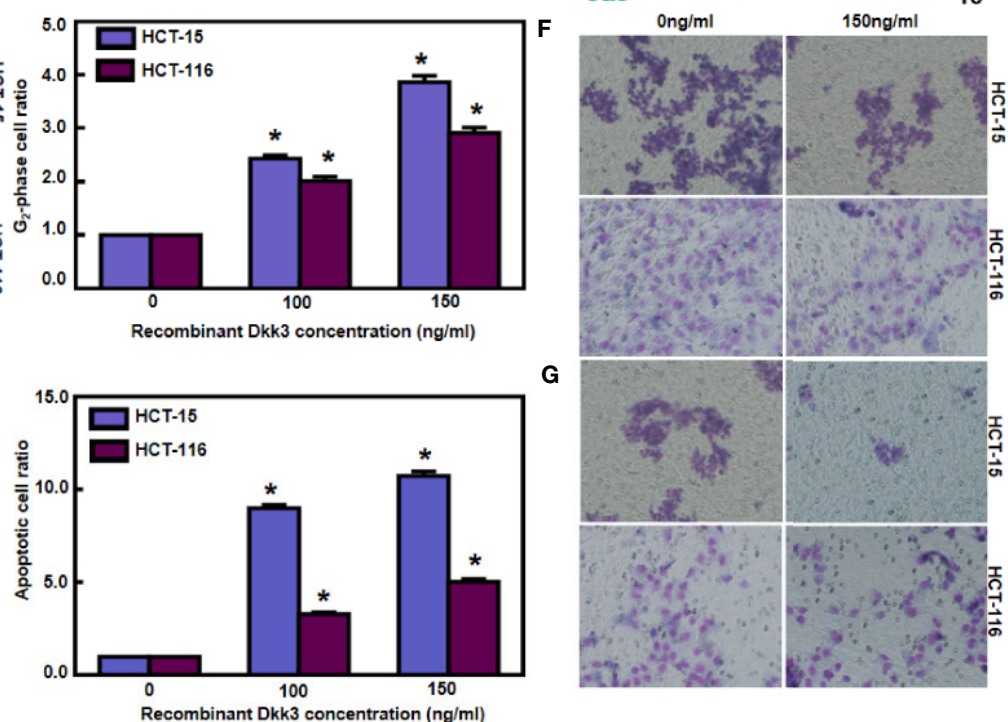

Ong/ml $\quad 150 \mathrm{ng} / \mathrm{ml}$
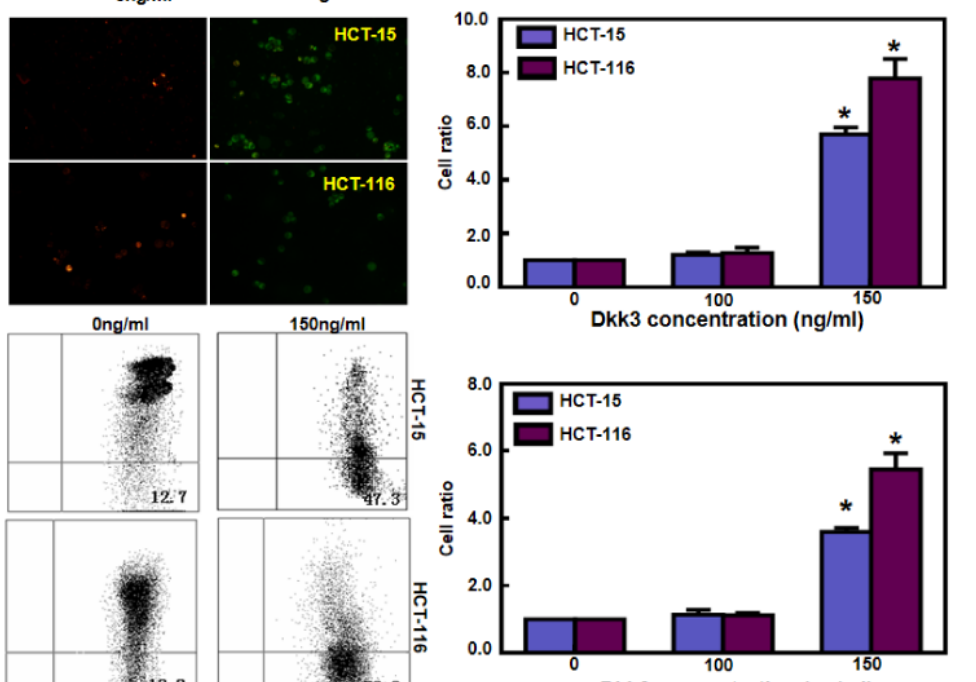

Dkk3 concentration (ng/ml)
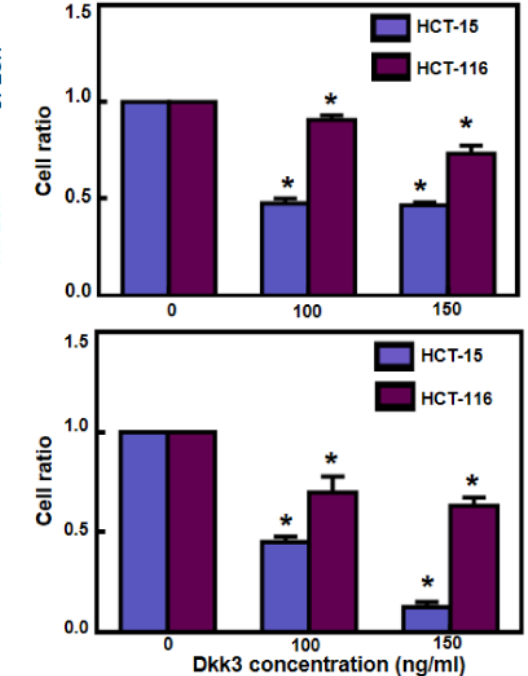

FIGURE 2 | Recombinant Dkk3 inhibited the aggressive phenotypes of colorectal cancer cells. Treatment with recombinant Dkk3 protein significantly suppressed the proliferation of HCT-15 and HCT-116, compared with the control cells (A). Recombinant Dkk3 protein could induce $\mathrm{G}_{2}$ arrest (B) and cell apoptosis (C) of both kinds of cells in a dose-dependent manner. JC-1 staining also demonstrated that

recombinant Dkk3 exposure significantly reduced mitochondrial membrane potential of the abovementioned cells treated with $150 \mathrm{ng} / \mathrm{mL}$ recombinant protein by fluorescence (D) and flow cytometry (E). After being exposed to recombinant Dkk3, both colorectal carcinoma cells exhibited a low ability to migrate $\mathbf{( F )}$ and invade (G), compared with the control cells. ${ }^{*} P<0.05$, compared with the control. 


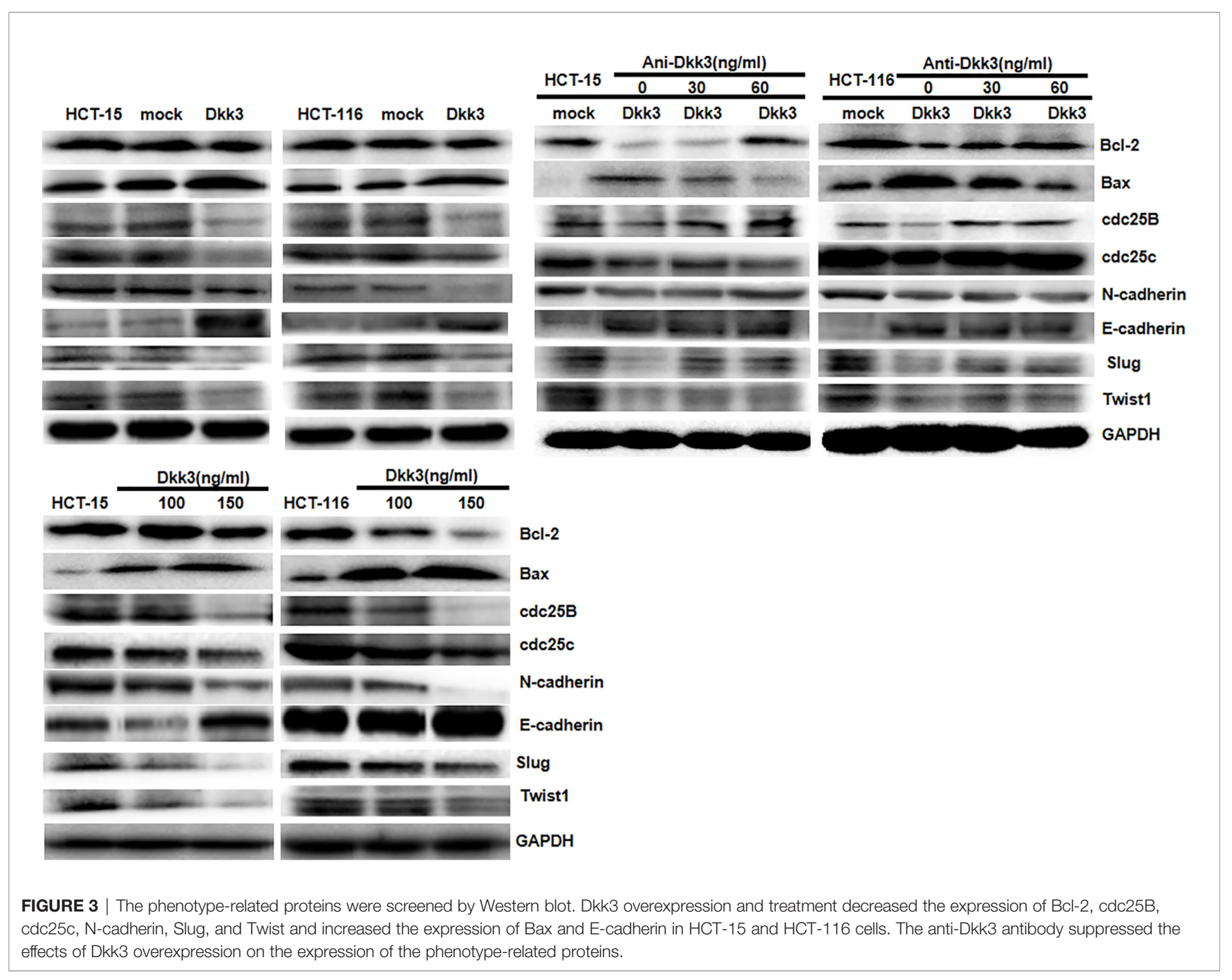

mucinous adenocarcinoma (Figure 5B, $p<0.05$ ). Levels of Dkk3 expression were higher in nested than in infiltrative adenocarcinomas (Figure 5B, $p<0.05$ ). However, these levels of expression were not correlated with gender, age, cell differentiation, lymph node or distal metastasis status, peritoneal spread, lymphatic and venous invasion, or tumor size in colorectal cancer patients ( $p>0.05$, data not shown).

Moreover, levels of $D k k 3$ mRNA expression were higher in colorectal cancer than in normal mucosa according to the Skrzypczak and Gaedcke method (Figure 6A); however, no difference was detected in TCGA database analysis (Figure 6B). These levels were positively associated with lymph node metastasis status in colorectal cancer patients (Figure 6B). In addition, colorectal cancer-associated fibroblasts had a higher level of Dkk3 expression compared to that observed in CD133+ or CD133- cancer cells (Figure 6C, $p<0.05$ ). There was no correlation between survival rate among colorectal cancer patients and $D k k 3$ expression levels ( $p>0.05$, data not shown). However, a negative relationship between Dkk3 mRNA expression and prognosis was observed in patients with stage
II or IV disease and in those with a high mutation burden (Figure 6D, $p<0.05$ ). Additionally, Dkk3 mRNA expression levels were correlated negatively with the rate of promoter methylation $(p<0.05$, data not shown). There was no association between $D k k 3$ promoter methylation and survival rates ( $p>0.05$, data not shown).

Dkk3 protein expression levels were lower in cancer than in normal tissues (Figure $7, p<0.05$ ). In addition, Dkk3 protein expression levels were lower in tubular than in mucinous adenocarcinomas $(p<0.05)$; similarly, they were lower in nested than in infiltrative adenocarcinomas $(p<0.05)$. However, Dkk3 protein expression levels did not correlate with gender, age, cell differentiation rate, lymph node or distal metastasis status, peritoneal spread, lymphatic and venous invasion, or tumor size in colorectal cancer patients $(p>0.05)$.

\section{Dkk3-Related Signal Pathways in Colorectal Cancer}

In GSEA, enriched Dkk3-related signaling pathways in colorectal cancer tissue included those associated with cellular adhesion 


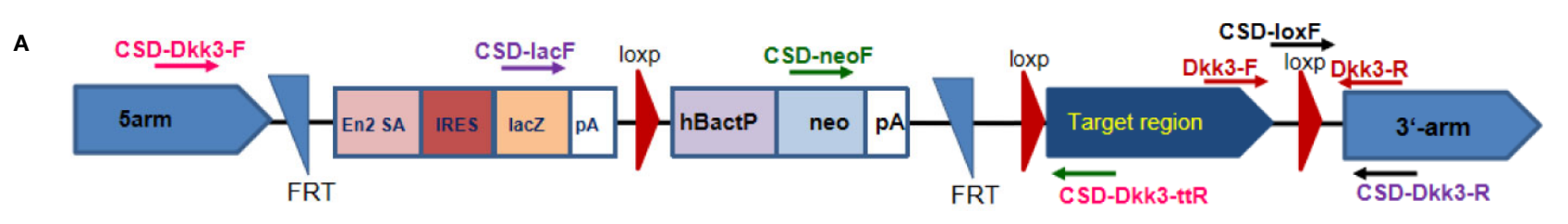

B

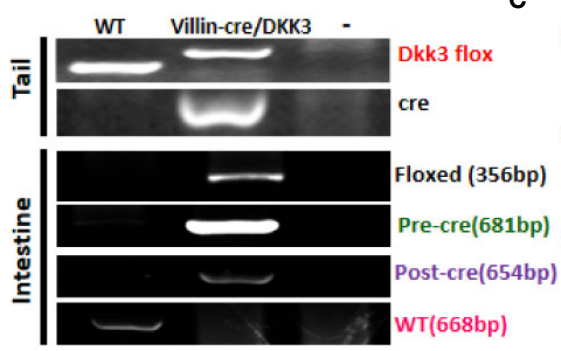

C

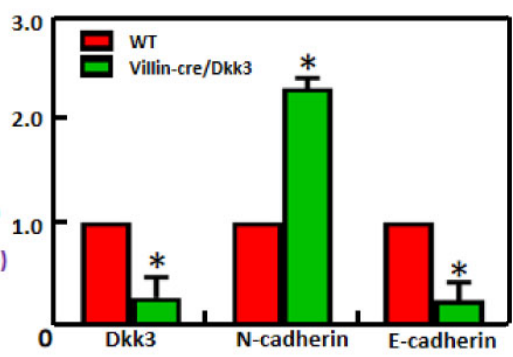

D

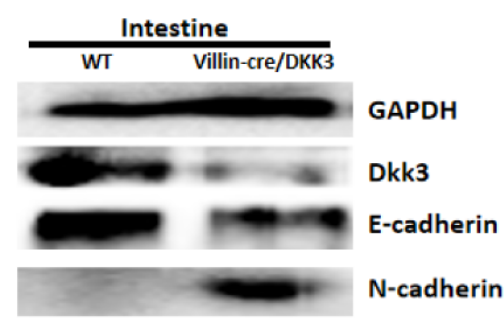

E

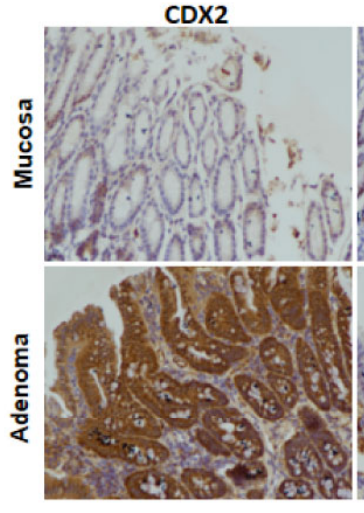

Ki-67

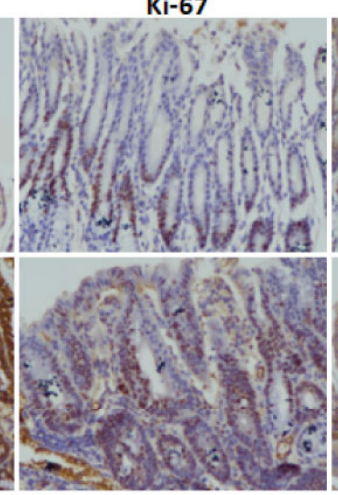

c-erB2

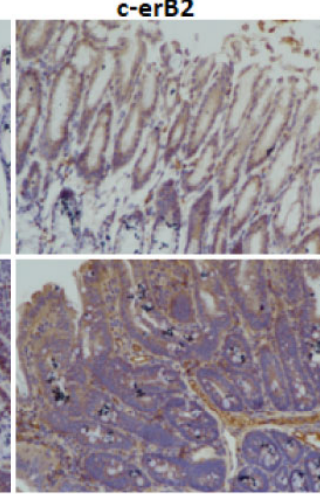

CEA

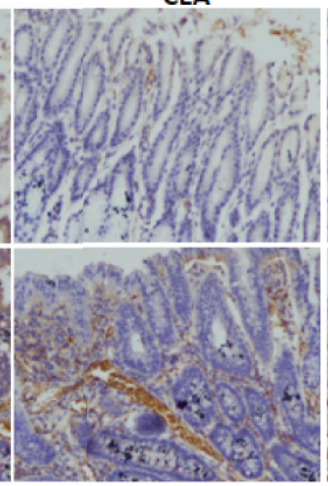

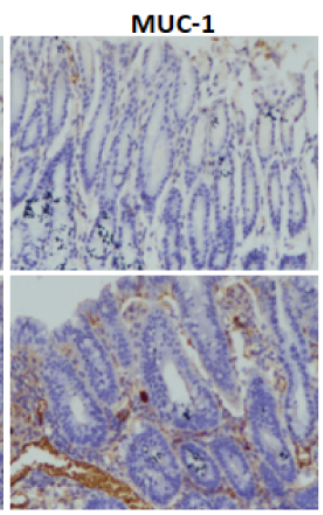

$\underline{50 \mu \mathrm{m}}$

FIGURE 4 | The effects of Dkk3 on tumor growth and carcinogenesis of colorectal cancer. PCR primers were designed (A) and subjected to PCR of tail and stomach DNA (B) with the same color for the corresponding primers and products. Expression of Dkk3, N-cadherin, and E-cadherin was confirmed by real-time PCR (C) and Western blot (D). Immunohistochemistry was employed to observe the maker proteins' expression in the intestinal adenoma of target villin-cre/Dkk3 knockout mice induced by sodium desoxycholate (E). " $p<0.05$, compared with the transfectant or knockout mice. WT, wild-type mice; VD, villin-cre +; Dkk3 -/-.

and migration, melanogenesis, chemokine, Hedgehog, JAKSTAT, TOLL-like receptor, TGF- $\beta$, MAPK, and calcium signaling (Table 1, $p<0.05$ ).

\section{DISCUSSION}

Shin et al. (22) reported that Dkk3 immunostaining was gradually downregulated from the epidermis in normal skin, actinic keratosis to squamous cell carcinoma (SCC). Dkk3 mRNA expression level was lower in SCC than in normal skin. In the present study, expression of $D k k 3 \mathrm{mRNA}$ and protein was downregulated in colorectal cancer cells, which is consistent with previous studies (12-17). A previous high-throughput study has shown a negative correlation between the level of $D k k 3$ mRNA expression and its promoter methylation rate (18). These findings suggest that Dkk3 expression is downregulated in colorectal cancer due to Dkk3 promoter methylation. Our previous study of gastric and lung cancer cells treated with 5Aza has shown a significantly negative association between Dkk3 promoter methylation and mRNA expression $(18,23)$. In a separate study, the rate of Dkk3 promoter methylation was higher in breast cancer than in normal tissue and was independently associated with adverse prognosis (24). Bioinformatics analysis has shown higher levels of Dkk3 mRNA in colorectal cancer; however, this finding might be accounted by between-study differences in methods used (RT-PCR, Western blot, and tissue microarray vs. RNA sequencing). Herein, we have shown that colorectal adenoma occurred in chemical-exposed and Dkk3deleted intestine, suggesting that Dkk3 abrogation might enhance chemically induced colorectal carcinogenesis.

Horikawa et al. (25) found that Dkk3 overexpression suppressed the proliferation of human bladder cancer cells by downregulating CD147 expression. Here, it was observed that both recombinant $\mathrm{Dkk} 3$ protein and $\mathrm{Dkk} 3$ overexpression might inhibit cell proliferation and trigger $G_{2}$ phase arrest in both colorectal 

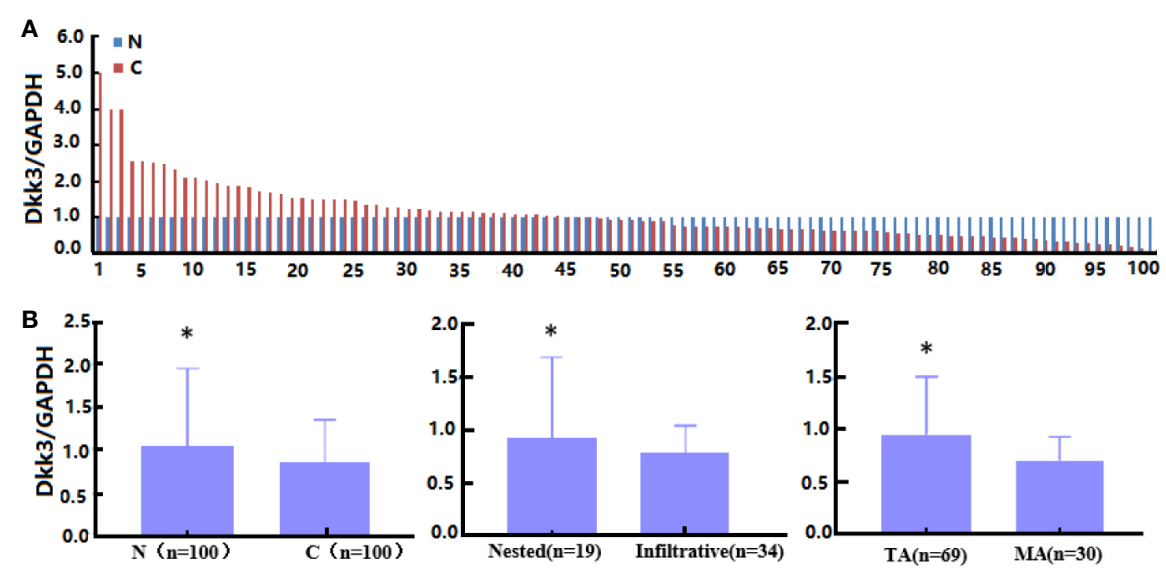

FIGURE 5 | The clinicopathological significance of Dkk3 mRNA expression in colorectal cancer. Real-time RT-PCR was employed to detect Dkk3 mRNA expression in colorectal cancer samples (A). Its expression was compared with pathological behaviors of colorectal cancer (B). N, normal; C, cancer, TA, tubular adenocarcinoma; MA, mucinous adenocarcinoma. ${ }^{*} p<0.05$.

cancer cell types. Previously, we observed that the presence of Dkk3 overexpression and recombinant $\mathrm{Dkk} 3$ triggered $\mathrm{G}_{1}$ phase arrest in gastric cancer cells by downregulating Cyclin D2 and Cyclin E expression via the $\mathrm{Wnt} / \beta$-catenin pathway (18). These data indicated that the effect of Dkk3 on the cell cycle depended on cell specificity. Additionally, a higher apoptosis rate was detected in both colorectal cancer cell types exposed to recombinant Dkk3 protein or transfected with Dkk3-expressing plasmid; this finding was consistent with that of our previous study (18). JC-1 staining showed that both treatments decreased mitochondrial membrane potential of colorectal cancer cells, suggesting both treatments induced colorectal cancer cell apoptosis via the mitochondrial pathway. Previously, we have reported on a positive relationship between Dkk3 and Caspase-3 expression in both colorectal and lung cancers $(21,23)$. It has been suggested that Dkk3 could cause c-JNK activation, mitochondrial translocation of Bax, and Bcl-2 under-expression in apoptotic induction (4). Shin et al. (22) have shown that Ad-Dkk3 induced JNK activation and subsequent apoptosis in lung cancer cells. It has been suggested that expression of cytosolic and secretory Dkk3 protein types might contribute to apoptotic induction of colorectal cancer cells via the mitochondrial pathway. Altogether, this evidence suggests that downregulated expression or loss of Dkk3 in colorectal cancer cells might disrupt the balance between apoptosis and proliferation.

In both gastric and colorectal cancers, Dkk3 expression was negatively correlated with the depth of invasion, lymph node involvement, and clinicopathological staging $(18,21)$; this finding was consistent with that of another study (26). Herein, the $D k k 3$ mRNA expression level was higher in nested than in filtrated cancer tissue, and recombinant Dkk3 and ectopic Dkk3 expression seemed to attenuate the migrative and invasive capacities of colorectal cancer cells, indicating that both kinds of intervention might effectively inhibit the risk of invasion or metastasis in advanced colorectal cancer. Dkk3-related signal pathways included cellular adhesion and migration in colorectal cancer, supporting this hypothesis. Hoang et al. (27) have previously reported that Dkk3 can inhibit invasion and motility of osteosarcoma cells via the $\mathrm{Wnt} / \beta$-catenin pathway. Meanwhile, adeno-Dkk3 gene delivery has been demonstrated to suppress tumor growth and the rate of invasion and metastasis of prostate cancer cells (10). Moreover, Dkk3 expression enhanced cellular adhesion and reduced the rate of cellular migration of melanoma cells (28). Than et al. (29) reported that intraperitoneal adeno-Dkk3 administration suppressed peritoneal dissemination of scirrhous gastric cancer. These findings suggest that invasive and metastatic properties of malignancies might be due to decreased expression levels or loss of Dkk3.

Zenzmaier et al. (30) report that plasma Dkk3 level was increased among older adults and that it might serve as a marker of senescence. Concurrently, the serum level of Dkk-3 was significantly lower in ovarian, gastric, and colorectal cancer patients than in healthy controls $(18,31,32)$. In contrast, serum Dkk3 concentration appeared higher in colorectal cancer patients than in healthy individuals; a similar finding was reported in a study of cervical cancer (32). In addition, we found higher supernatant Dkk3 level in Dkk3 transfectants of colorectal and gastric cancer cells (18). Dkk3 treatment caused the same results as Dkk3 overexpression in line with our data (18, 23), which could be blocked with anti-Dkk3 antibody (18). Zhang et al. (33) reported that soluble Dkk-3 protein levels were associated with prostate acinar growth. It has been proposed that soluble Dkk3 protein may bind to transmembrane co-receptor Lrp6 to suppress Wnt/ $\beta$-catenin signaling $(4,34)$. As a result, we hypothesized that recombinant $\mathrm{Dkk} 3$ might bind to receptors to reverse aggressive phenotypes of gastrointestinal cancer cells in either an autocrine or a paracrine manner (17).

Dkk3 expression has been shown to induce $\beta$-catenin degradation by interacting with protoesome $\beta \operatorname{TrCP}$, blocking the effect of nuclear $\beta$-catenin on TCF- 4 activity, and suppressing the expression of TCF- 4 targets (c-myc, VEGF and cylcin D) (17, 35). The human dynein light chain, Tctex-1, may interact with 
A
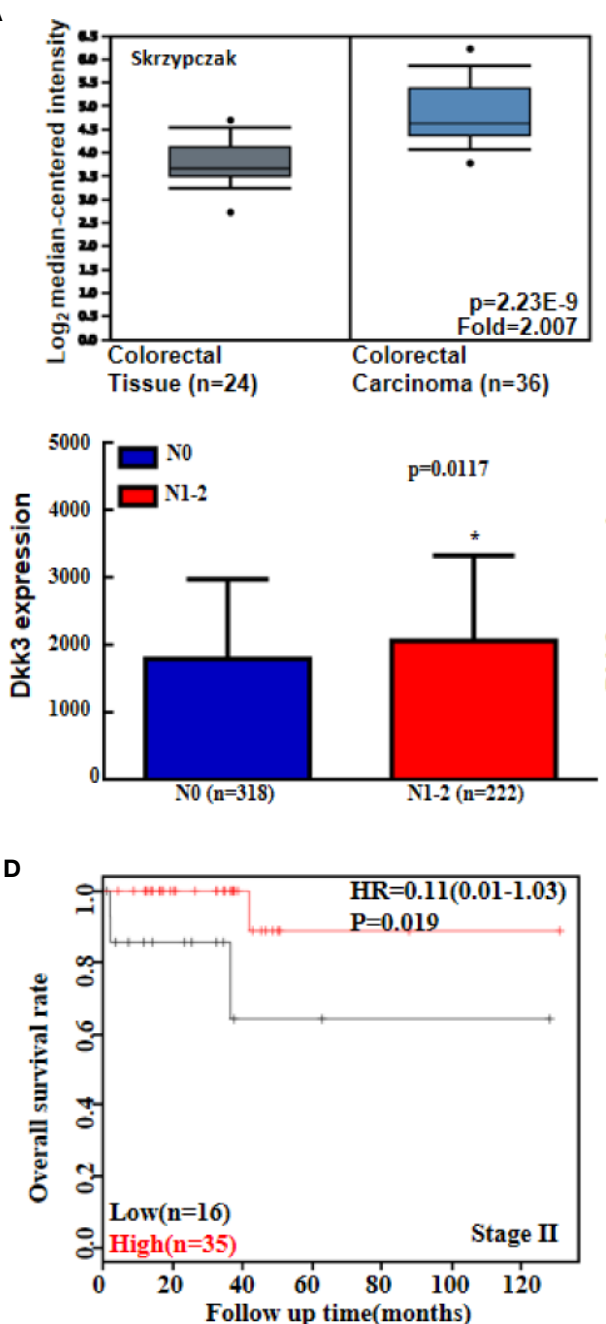
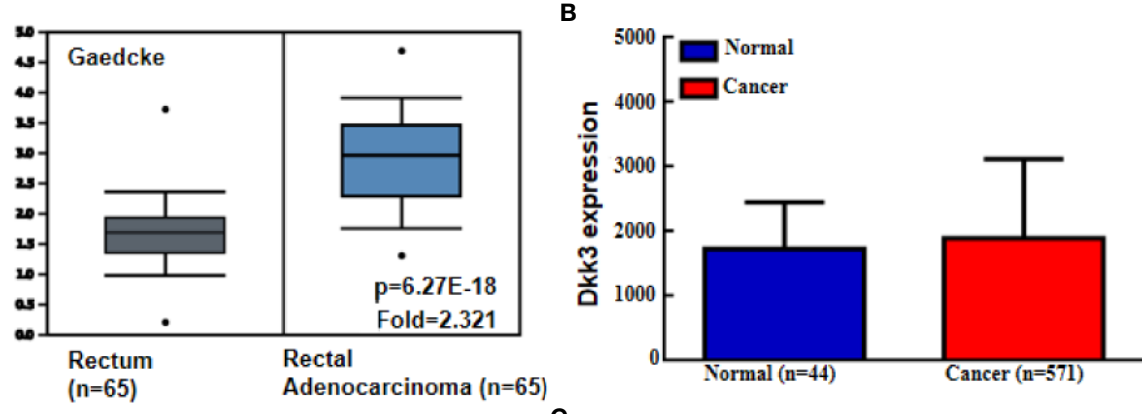

C ${ }^{15000}$ -
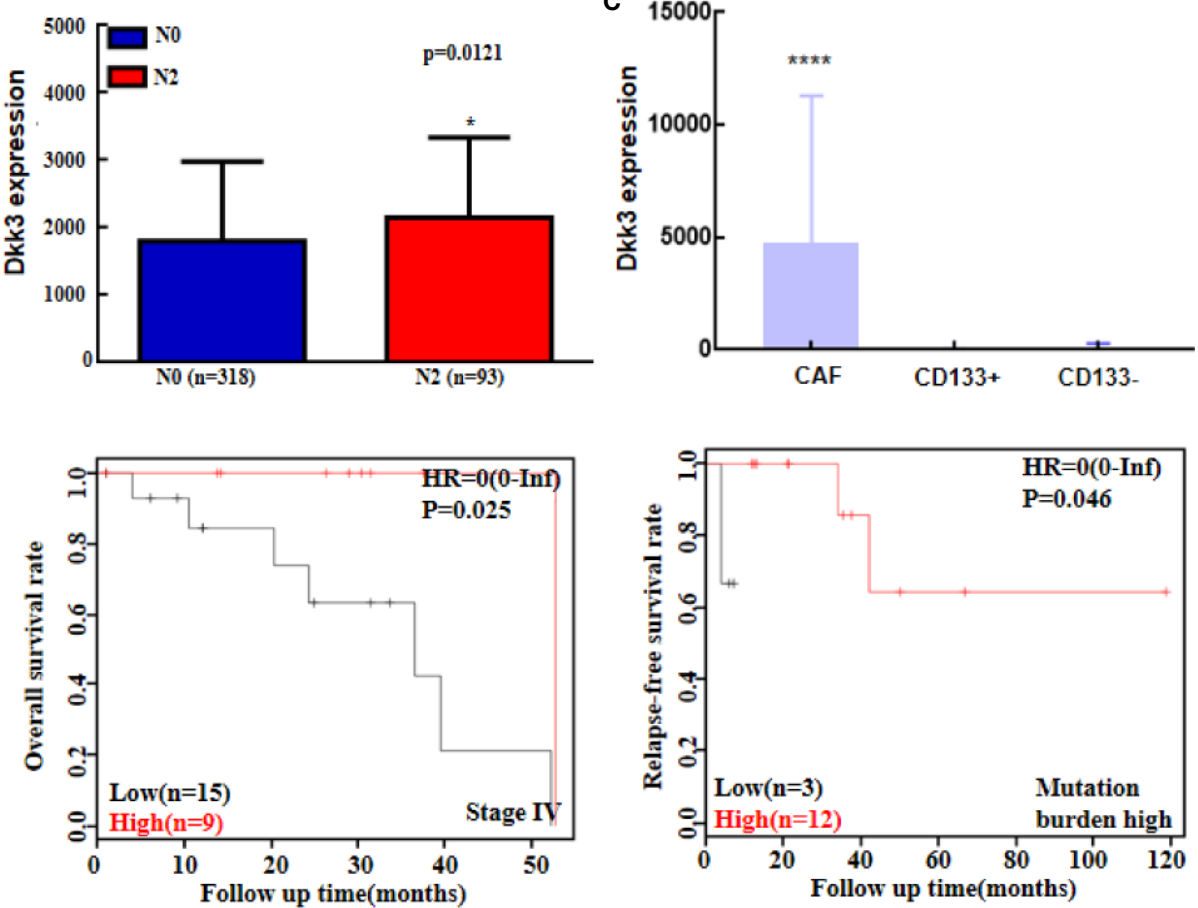

FIGURE 6 | The bioinformatics analysis of Dkk3 mRNA expression in colorectal cancer. Oncomine (A) and TCGA (B) data sets were employed to analyze Dkk3 expression in colorectal cancer, and its expression was compared with pathological parameters of cancers. Dkk3 mRNA expression was higher in cancer-associated fibroblasts (CAF) than CD133-positive (CD133+) and -negative (CD133-) colorectal cancer cells (C). Kaplan-Meier curves were used to analyze the prognostic significance of $D k k 3$ mRNA expression according to KM plotters (D). HR, hazard ratio; $N$, lymph node metastasis. ${ }^{*} p<0.05 ;{ }^{* \star \star} p<0.001$. 

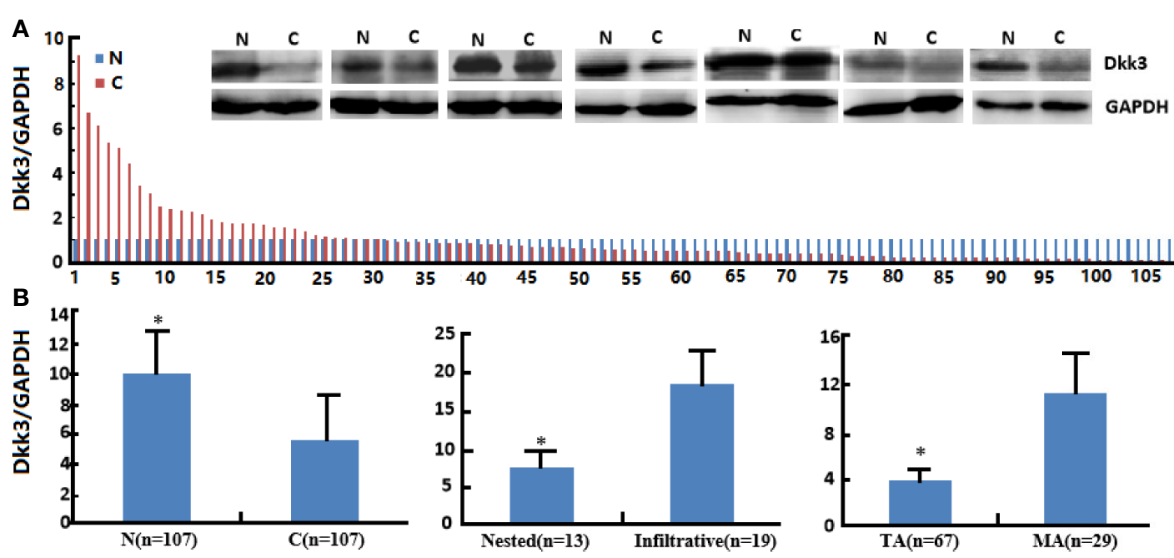

FIGURE 7 | The clinicopathological significance of Dkk3 protein expression in colorectal cancer. Western blot was employed to detect Dkk3 protein expression in colorectal cancer samples (A). Its expression was compared with pathological behaviors of colorectal cancer (B). N, normal; C, cancer, TA, tubular adenocarcinoma; MA, mucinous adenocarcinoma. ${ }^{*} p<0.05$.

TABLE 1 | Dkk3-enriched signal pathway in colorectal cancer according KEGG analysis.

\begin{tabular}{lcc}
\hline Pathway & Size & $\boldsymbol{P}$ value \\
\hline Focal adhesion & 197 & $<0.001$ \\
Gap junction & 87 & $<0.001$ \\
Cytokine -cytokine receptor interaction & 234 & $<0.001$ \\
Cell adhesion molecules CAMS & 129 & $<0.001$ \\
Dilated cardiomyopathy & 86 & $<0.001$ \\
Chemokine signaling pathway & 183 & $<0.001$ \\
Hypertrophic cardiomyopathy & 79 & $<0.001$ \\
Leukocyte transendothelial migration & 111 & $<0.001$ \\
Hedgehog signaling pathway & 54 & $<0.001$ \\
Regulation of actin cytoskeleton & 207 & $<0.001$ \\
Melanogenesis & 99 & $<0.001$ \\
ECM receptor interaction & 83 & $<0.001$ \\
Axon guidance & 127 & $<0.001$ \\
Pathways in cancer & 322 & $<0.001$ \\
Basal cell carcinoma & 54 & $<0.001$ \\
Arrhythmogenic right ventricular cardiomyopathy & 71 & 0.001 \\
Complement and coagulation cascades & 64 & 0.001 \\
Neuroactive ligand receptor interaction & 231 & 0.001 \\
JAK-STAT signaling pathway & 130 & 0.001 \\
Leishmania infection & 70 & 0.005 \\
TOLL-like receptor signaling pathway & 87 & 0.006 \\
Glycosaminoglycan biosynthesis chondroitin sulfate & 22 & 0.006 \\
Vascular smooth muscle contraction & 113 & 0.006 \\
Hematopoietic cell lineage & 81 & 0.006 \\
Calcium signaling pathway & 169 & 0.007 \\
TGF- $\beta$ signaling pathway & 85 & 0.009 \\
MAPK signaling pathway & 257 & 0.015 \\
Glycosaminoglycan biosynthesis heparan sulfate & 26 & 0.02 \\
Melanoma & 70 & 0.039 \\
\hline & &
\end{tabular}

Dkk3, which might be involved in ER stress and intracellular dynein motor dynamics (36). However, a separate study has reported that Dkk3-carrying adenovirus infection of normal human fibroblasts induced interleukin-7 production, triggered by ER stress proteins (ASK1, p38, IRE1 $\alpha$ and IRF-1) (37). The repressing effects of Dkk3 overexpression on aggressive colorectal cancer cell phenotypes might be due to a higher rate of secretion of its soluble form alongside interaction of its cytosolic and other types of protein.

In this study, hypoexpression of cdc25B and $\mathrm{cdc} 25 \mathrm{c}$ was associated with the suppressing effects of Dkk3 on proliferation and tumor growth as cdc25B activates Cyclin-dependent kinase CDC2 required for mitosis progression; concurrently, cdc25C promotes Cyclin B-Cdk1 complex formation required for $\mathrm{G}_{2} / \mathrm{M}$ phase transition (38). The presence of Bax-Bcl-2 complex on the mitochondrial membrane can lower the rate of apoptosis as Bax can open the mitochondrial anion channel to initiate apoptosis (39). Consequently, Bax hyperexpression and Bcl-2 hyperexpression may explain the inductive effect of Dkk3 in apoptosis of colorectal cancer cells. Slug and twist promoted epithelial-mesenchymal transition (EMT) alongside E-cadherin under-expression and N-cadherin hyperexpression (40); downregulated expression of $\mathrm{N}$-cadherin and of slug and twist, and upregulation of E-cadherin might result in the inhibitory effects of Dkk3 in EMT of colorectal cancer cells.

It has been reported that Dkk3 might orchestrate concomitant activation of $\beta$-catenin and YAP/TAZ in cancer-associated fibroblasts (CAFs) by interfering with the Kremen negative regulator and increasing cell-surface levels of LRP6 as an HSF1 effector, required to promote tumor aggressiveness (41). Zhou et al. (42) demonstrated that Dkk3 was produced by pancreatic stellate cells and stimulated tumor growth, metastasis, and chemoresistance of pancreatic ductal adenocarcinoma in the paracrine and autocrine manner via the NF- $\mathrm{BB}$ pathway. Zenzmaier et al. (43) found that Dkk-3 promoted fibroblast proliferation and myofibroblast differentiation and regulated angiopoietin-1 expression in prostatic stroma potentially by enhancing PI3K/Akt signaling, which triggered angiogenesis in prostate cancer. Our bioinformatics data showed higher Dkk3 expression in CAF than in CD133+ or in CD133- cancer cells, supporting the hypothesis that Dkk3 in cancer stromal cells might be involved in cancer progression. 
Dkk3 was positively associated with survival rate among patients with nasopharyngeal carcinoma (26). Yang et al. (23) found that $D k k 3$ mRNA overexpression positively correlated with overall, progression-free, and post-progression survival rates among lung cancer patients even when stratified by sex, histological subtyping, disease grade, TNM stage, chemotherapy and radiotherapy type, or smoking status. Herein, Kaplan-Meier analysis indicated that mRNA expression or promoter methylation of $D k k 3$ was not linked to overall survival rate among colorectal cancer patients; this finding was consistent with that of our immunostaining tests (21). Moreover, Dkk3 expression had no prognostic significance in colorectal cancer at either mRNA or protein level. However, its mRNA expression was negatively correlated with poor prognosis among colorectal cancer patients with Stage II and IV disease and among those with a high mutation burden; these findings might provide guidance for clinical practice.

In conclusion, Dkk3 expression was downregulated in colorectal cancer tissue due to its promoter methylation; this finding can be used in assessing cancer aggressiveness. Recombinant Dkk3 protein and forced Dkk3 overexpression might suppress aggressive phenotypes of colorectal cancer cells. These findings indicate that Dkk3 might be a promising target for gene therapy in colorectal cancer if it can specifically be expressed in cancer cells. However, future studies need to elucidate Dkk3 receptor or partner and the associated signaling pathway.

\section{DATA AVAILABILITY STATEMENT}

The raw data supporting the conclusions of this article will be made available by the authors, without undue reservation.

\section{REFERENCES}

1. Tsuji T, Miyazaki M, Sakaguchi M, Inoue Y, Namba M. A Dkk3 gene shows down-regulation in human immortalized cells and human tumor-derived cell lines. Biochem Biophys Res Commun (2000) 268(1):20-4. doi: 10.1006/ bbrc.1999.2067

2. Hsieh SY, Hsieh PS, Chiu CT, Chen WY. Dickkopf-3/REIC functions as a suppressor gene of tumor growth. Oncogene (2004) 23(57):9183-9. doi: 10.1038/sj.onc. 1208138

3. Kataoka K, Maehara N, Ayabe Y, Murata H, Huh NH, Sakaguchi M. Tumor necrosis factor- $\alpha$ downregulates the REIC/Dkk-3 tumor suppressor gene in normal human skin keratinocytes. Mol Med Rep (2018) 17(5):6661-6. doi: 10.3892/mmr.2018.8676

4. Abarzua F, Sakaguchi M, Takaishi M, Nasu Y, Kurose K, Ebara S, et al. Adenovirus-mediated overexpression of REIC/Dkk-3 selectively induces apoptosis in human prostate cancer cells through activation of c-Jun-NH2kinase. Cancer Res (2005) 65(21):9617-22. doi: 10.1158/0008-5472.CAN-050829

5. Tanimoto R, Sakaguchi M, Abarzua F, Kataoka K, Kurose K, Murata H, et al. Down-regulation of BiP/GRP78 sensitizes resistant prostate cancer cells to gene-therapeutic overexpression of REIC/Dkk-3. Int J Cancer (2010) 126 (7):1562-9. doi: 10.1002/ijc.24764

6. Abarzua F, Sakaguchi M, Tanimoto R, Sonegawa H, Li DW, Edamura K, et al. Heat shock proteins play a crucial role in tumor-specific apoptosis by REIC/ Dkk-3. Int J Mol Med (2007) 20(1):37-43. doi: 10.3892/ijmm.20.1.37

7. Takata A, Terauchi M, Hiramitsu S, Uno M, Wakana K, Kubota T. Dkk-3 induces apoptosis through mitochondrial and Fas death receptor pathways in

\section{ETHICS STATEMENT}

The studies involving human participants were reviewed and approved by Affiliated Hospital of Chengde Medical University. The patients/participants provided their written informed consent to participate in this study. The animal study was reviewed and approved by Affiliated Hospital of Chengde Medical University. Written informed consent was obtained from the owners for the participation of their animals in this study.

\section{AUTHOR CONTRIBUTIONS}

SZ, C-lH, E-hZ, H-mJ, and H-cZ designed and carried out the experiment, and $\mathrm{H}-\mathrm{cZ}$ wrote the manuscript. All authors contributed to the article and approved the submitted version.

\section{FUNDING}

This study was supported by Award for Liaoning Distinguished Professor, and National Natural Scientific Foundation of China (81672700).

\section{ACKNOWLEDGMENTS}

Conditional $D k k 3$ knockout mice were kindly presented by Prof. Kumon, Department of Urology, Okayama University, Japan, and pCDNA3.1-Dkk3 plasmid was kindly presented by Yoshifumi Mizobuchi, University of Tokushima, Japan.

human mucinous ovarian cancer cells. Int J Gynecol Cancer (2015) 25(3):3729. doi: 10.1097/IGC.0000000000000340

8. Xu J, Sadahira T, Kinoshita R, Li SA, Huang P, Wada K, et al. Exogenous DKK-3/ REIC inhibits Wnt/ $\beta$-catenin signaling and cell proliferation in human kidney cancer KPK1. Oncol Lett (2017) 14(5):5638-42. doi: 10.3892/ol.2017.6833

9. Kinoshita R, Watanabe M, Huang P, Li SA, Sakaguchi M, Kumon H, et al. The cysteine-rich core domain of REIC/Dkk-3 is critical for its effect on monocyte differentiation and tumor regression. Oncol Rep (2015) 33(6):2908-14. doi: 10.3892/or.2015.3885

10. Edamura K, Nasu Y, Takaishi M, Kobayashi T, Abarzua F, Sakaguchi M, et al. Adenovirus-mediated REIC/Dkk-3 gene transfer inhibits tumor growth and metastasis in an orthotopic prostate cancer model. Cancer Gene Ther (2007) 14(9):765-72. doi: 10.1038/sj.cgt.7701071

11. Kobayashi K, Ouchida M, Tsuji T, Hanafusa H, Miyazaki M, Namba M, et al. Reduced expression of the REIC/Dkk-3 gene by promoter-hypermethylation in human tumor cells. Gene (2002) 282(1-2):151-8. doi: 10.1016/S0378-1119 (01)00838-1

12. Kurose K, Sakaguchi M, Nasu Y, Ebara S, Kaku H, Kariyama R, et al. Decreased expression of REIC/Dkk-3 in human renal clear cell carcinoma. J Urol (2004) 171(3):1314-8. doi: 10.1097/01.ju.0000101047.64379.d4

13. Tsuji T, Nozaki I, Miyazaki M, Sakaguchi M, Pu H, Hamazaki Y, et al. Antiproliferative activity of REIC/Dkk-3 and its significant down-regulation in non-small-cell lung carcinomas. Biochem Biophys Res Commun (2001) 289 (1):257-63. doi: 10.1006/bbrc.2001.5972

14. Nozaki I, Tsuji T, Iijima O, Ohmura Y, Andou A, Miyazaki M, et al. Reduced expression of REIC/Dkk-3 gene in non-small cell lung cancer. Int J Oncol (2001) 19(1):117-21. doi: 10.3892/ijo.19.1.117 
15. Tanimoto R, Abarzua F, Sakaguchi M, Takaishi M, Nasu Y, Kumon H, et al. REIC/ Dkk-3 as a potential gene therapeutic agent against human testicular cancer. Int J Mol Med (2007) 19(3):363-8. doi: 10.3892/ijmm.19.3.363

16. Ding Z, Qian YB, Zhu LX, Xiong QR. Promoter methylation and mRNA expression of DKK-3 and WIF-1 in hepatocellular carcinoma. World $J$ Gastroenterol (2009) 15(21):2595-601. doi: 10.3748/wjg.15.2595

17. Lee EJ, Jo M, Rho SB, Park K, Yoo YN, Park J, et al. Dkk3, downregulated in cervical cancer, functions as a negative regulator of beta-catenin. Int J Cancer (2009) 124(2):287-97. doi: 10.1002/ijc.23913

18. Xu XY, Xia P, Yu M, Nie XC, Yang X, Xing YN, et al. The roles of Dkk3 gene and its encoding product in gastric carcinoma. Cell Cycle (2012) 11(7):141431. doi: $10.4161 / \mathrm{cc} .19823$

19. Colorectal cancer facts and figures. Am Cancer Soc (2005).

20. Yoshida D, Kono S, Moore MA, Toyomura K, Nagano J, Mizoue T, et al. Colorectal polypectomy and risk of colorectal cancer by subsite: the Fukuoka Colorectal Cancer study. Jpn J Clin Oncol (2007) 37(8):597-602. doi: 10.1093/ jjco/hym065

21. Wang W, Zhu W, Xu XY, Nie XC, Yang X, Xing YN, et al. The clinicopathological significance of Dkk3 expression in colorectal carcinomas. Histol Histopathol (2012) 27(6):735-43. doi: 10.14670/HH-27.735

22. Shin JM, Choi DK, Kang HY, Sohn KC, Lee Y, Kim CD, et al. The expression pattern and functional role of REIC/Dkk-3 in the development of cutaneous squamous cell carcinoma. J Dermatol Sci (2016) 84(1):88-96. doi: 10.1016/ j.jdermsci.2016.06.006

23. Yang L, Zhao S, Xia P, Zheng HC. Down-regulated Dkk3expression in lung carcinogenesis: a molecular target for gene therapy. Histol Histopathol (2018) 33(7):691-704. doi: 10.14670/HH-11-964

24. Veeck J, Wild PJ, Fuchs T, Schüffler PJ, Hartmann A, Knüchel R, et al. Prognostic relevance of Wnt-inhibitory factor-1 (WIF1) and Dickkopf-3 (DKK3) promoter methylation in human breast cancer. BMC Cancer (2009) 9:217. doi: 10.1186/1471-2407-9-217

25. Horikawa Y, Watanabe M, Sadahira T, Ariyoshi Y, Kobayashi Y, Araki M, et al. Overexpression of REIC/Dkk-3 suppresses the expression of CD147 and inhibits the proliferation of human bladder cancer cells. Oncol Lett (2017) 14 (3):3223-8. doi: 10.3892/ol.2017.6548

26. Pang $Q, H u W$, Zhang $X$, Pang $M$. Wnt/ $\beta$-Catenin signaling pathway-related proteins (DKK-3, $\beta$-Catenin, and c-MYC) are involved in prognosis of nasopharyngeal carcinoma. Cancer Biother Radiopharm (2019) 34(7):43643. doi: $10.1089 / \mathrm{cbr} .2019 .2771$

27. Hoang BH, Kubo T, Healey JH, Yang R, Nathan SS, Kolb EA, et al. Dickkopf 3 inhibits invasion and motility of Saos- 2 osteosarcoma cells by modulating the Wnt-beta-catenin pathway. Cancer Res (2004) 64(8):2734-9. doi: 10.1158/ 0008-5472.CAN-03-1952

28. Kuphal S, Lodermeyer S, Bataille F, Schuierer M, Hoang BH, Bosserhoff AK. Expression of Dickkopf genes is strongly reduced in malignant melanoma. Oncogene (2006) 25(36):5027-36. doi: 10.1038/sj.onc.1209508

29. Than SS, Kataoka K, Sakaguchi M, Murata H, Abarzua F, Taketa C, et al. Intraperitoneal administration of an adenovirus vector carrying REIC/Dkk-3 suppresses peritoneal dissemination of scirrhous gastric carcinoma. Oncol Rep (2011) 25(4):989-95. doi: 10.3892/or.2011.1149

30. Zenzmaier C, Sklepos L, Berger P. Increase of Dkk-3 blood plasma levels in the elderly. Exp Gerontol (2008) 43(9):867-70. doi: 10.1016/j.exger.2008.05.012
31. Safari E, Mosayebi G, Khorram S. Dkk-3 as a potential biomarker for diagnosis and prognosis of colorectal cancer. Med J Islam Repub Iran (2018) 32:86. doi: 10.14196/mjiri.32.86

32. Jiang T, Huang L, Wang S, Zhang S. Clinical significance of serum Dkk-3 in patients with gynecological cancer. J Obstet Gynaecol Res (2010) 36(4):769-73. doi: 10.1111/j.1447-0756.2010.01234.x

33. Zhang K, Watanabe M, Kashiwakura Y, Li SA, Edamura K, Huang P, et al. Expression pattern of REIC/Dkk-3 in various cell types and the implications of the soluble form in prostatic acinar development. Int J Oncol (2010) 37 (6):1495-501. doi: 10.3892/ijo_00000802

34. Nakamura RE, Hackam AS. Analysis of Dickkopf3 interactions with Wnt signaling receptors. Growth factors (Chur Switzerland) (2010) 28(4):232-42. doi: 10.3109/08977191003738832

35. Yue W, Sun Q, Dacic S, Landreneau RJ, Siegfried JM, Yu J, et al. Downregulation of Dkk3 activates beta-catenin/TCF-4 signaling in lung cancer. Carcinogenesis (2008) 29(1):84-92. doi: 10.1093/carcin/bgm267

36. Ochiai K, Watanabe M, Ueki H, Huang P, Fujii Y, Nasu Y, et al. Tumor suppressor REIC/ Dkk-3 interacts with the dynein light chain, Tctex-1. Biochem Biophys Res Commun (2011) 412(2):391-5. doi: 10.1016/ j.bbrc.2011.07.109

37. Sakaguchi M, Kataoka K, Abarzua F, Tanimoto R, Watanabe M, Murata H, et al. Overexpression of REIC/Dkk-3 in normal fibroblasts suppresses tumor growth via induction of interleukin-7. J Biol Chem (2009) 284(21):14236-44. doi: 10.1074/jbc.M808002200

38. Laphanuwat P, Jirawatnotai S. Immunomodulatory roles of cell cycle regulators. Front Cell Dev Biol (2019) 7:23. doi: 10.3389/fcell.2019.00023

39. D'Arcy MS. Cell death: a review of the major forms of apoptosis, necrosis and autophagy. Cell Biol Int (2019) 43(6):582-92. doi: 10.1002/cbin.11137

40. Aiello NM, Kang Y. Context-dependent EMT programs in cancer metastasis. J Exp Med (2019) 216(5):1016-26. doi: 10.1084/jem.20181827

41. Ferrari N, Ranftl R, Chicherova I, Slaven ND, Moeendarbary E, Farrugia AJ, et al. Dickkopf-3 links HSF1 and YAP/TAZ signalling to control aggressive behaviours in cancer-associated fibroblasts. Nat Commun (2019) 10:130. doi: 10.1038/s41467-018-07987-0

42. Zhou L, Husted H, Moore T, Lu M, Deng D, Liu Y, et al. Suppression of stromal-derived Dickkopf-3 (DKK3) inhibits tumor progression and prolongs survival in pancreatic ductal adenocarcinoma. Sci Transl Med (2018) 10 (464):3487. doi: 10.1126/scitranslmed.aat3487

43. Zenzmaier C, Sampson N, Plas E, Berger P. Dickkopf-related protein 3 promotes pathogenic stromal remodeling in benign prostatic hyperplasia and prostate cancer. Prostate (2013) 73(13):1441-52. doi: 10.1002/pros.22691

Conflict of Interest: The authors declare that the research was conducted in the absence of any commercial or financial relationships that could be construed as a potential conflict of interest.

Copyright (c) 2020 Zhao, Hao, Zhao, Jiang and Zheng. This is an open-access article distributed under the terms of the Creative Commons Attribution License (CC BY). The use, distribution or reproduction in other forums is permitted, provided the original author(s) and the copyright owner(s) are credited and that the original publication in this journal is cited, in accordance with accepted academic practice. No use, distribution or reproduction is permitted which does not comply with these terms. 